\title{
Mitigation of Commutation Torque Ripples in Permanent Magnet Brushless DC Motor
}

\author{
M.Arun Noyal Doss", V.Ganapathy, Subhranshu Sekhar Dash, V.Marthandan, D.Mahesh \\ Department of Electrical and Electronics, SRM University \\ *Corresponding Author: arunnoyal@gmail.com
}

Copyright $(2013$ Horizon Research Publishing All rights reserved.

\begin{abstract}
In a conventional three phase Brushless DC machine with $120^{\circ}$ electrical conduction, Harmonics and commutation torque ripple occurs because of changeover of load current from one phase to another at every 60 electrical degrees. This paper presents techniques for diminishing the harmonics and torque ripples in sensor Brushless DC motor. This torque ripple reduction techniques based on voltage controlled and current controlled algorithm, both results are simulated and compared to bring out suitable and effective method.
\end{abstract}

Keywords Brushless DC Motor, Harmonics And Torque Ripples

\section{Introduction}

The conventional Brushed DC motor uses mechanical brushes and commutator, so it requires lot of maintenance, it creates noise and arcing. The Brushless DC motor could overcome this issue by replacing mechanical commutator by electronic commutator, which includes three phase inverter, rotor position sensor and controller circuit. Brushless DC motor contains permanent magnet rotor and three phase stator winding, it is connected with the three phase inverter.it means Brushless DC motor uses power electronic switches for the commutation purpose. Normally power electronic switches are operates in high frequency, so it creates harmonics and torque ripple, this torque ripple produces noise and degrade in speed-control characteristics. The torque ripple and the harmonics are the main issue in Brushless DC motor, in order to minimize harmonics and torque ripple the current controlled method with two level and multilevel inverter is used and also the voltage controlled method with filter is used. The paper [1] presents design of current control method and duty cycle of pulse width modulation (PWM) is regulated in real time by measuring the wave function of back EMF. The torque ripple is reduced by varying the input voltage is presented in paper [2]. A simple method for reducing commutation torque ripple by modifying the voltage of decaying phase in commutation interval is presented in paper [3].The paper [4] presents measurement of commutation interval from the terminal voltage of BLDC motor and it is also calculates PWM duty ratio using the measured commutation interval to suppress the commutation torque ripple. This paper [5] describes a new PWM switching strategy to minimize the torque ripples in BLDC motor which is based on sensor rotor position control. A novel indirect position detection and an improved methodology to reduce the high frequency harmonics content and torque ripples using $\mathrm{RC}$ filter connected at the input of the BLDC motor is presented in paper [6]-[9].The harmonics and torque ripple is reduced by the voltage control method and with filter is presented in paper [9]-[11].The commutation of a brushless DC motor depends on position of rotor. The angle between magneto-motive force of stator and rotor is fixed to $90^{\circ}$ (electrical) so the motor produces maximum torque and needs low reactive current which is useful for advance commutation by few degrees to compensate the stray inductance effects and minimize reactive current.

\section{Current Control Method}

The overall block diagram of the planned system for current controller to minimize harmonics and torque ripple is shown in Fig.1. The operation of the system is as follows: the armature current is sensed through current sensors and converted into voltage signals. These signals are then rectified and a dc component, with the value of the ceiling of the current Idc is obtained. The proportional-integral (PI) controller is employed that contains a feedback signal derived from the armature current. The current controller block with tri-angular carrier wave is shown in Fig.2.

The PI controller is tuned by well-known method called Ziegler Nichols method. The generated PWM pattern and the information given by the position sensor generate the modulation signals for each transistor produced. The PWM pattern controls the magnitude and position sensor determines the PWM pattern applied to six transistors creating correct sequence for the rotation of the machine. 


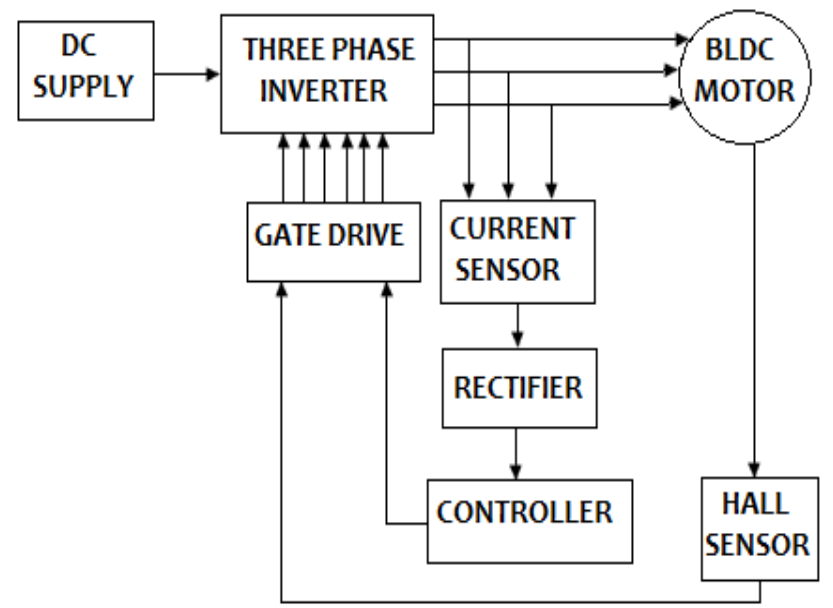

Figure 1. Block diagram of a current controller

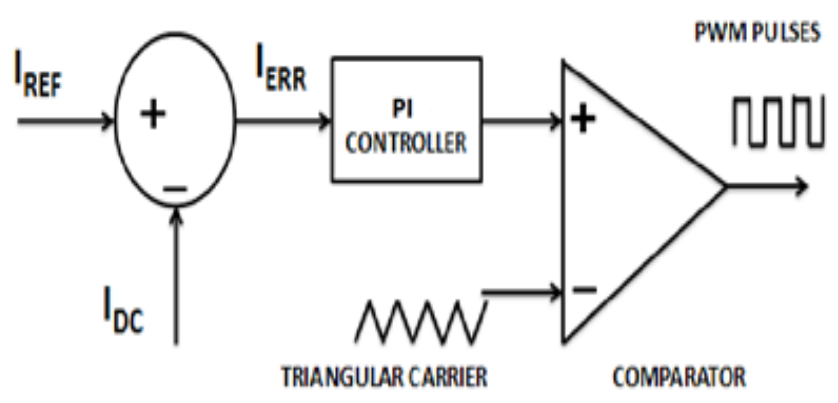

Figure 2. Current controller block

\section{Voltage Control Method}

The BLDC motor is energized by three phase inverter through an Inductor - Capacitor filter for reducing the high frequency component. The capacitor voltage value has to be selected in such a way that it can charge and discharge in an effective manner to reduce the high frequency component.Fig.3.shows overall block diagram of voltage controller. The inductor- capacitor filter for the proposed work is connected in the interface of the drive and the motor. The LC filter in this system acts as a low pass filtering circuit which offer high impedance to high frequency component of the voltage and very minimum impedance to the power frequency voltage components and thereby minimizes harmonics in the supply voltage to the motor and the series inductance opposes the sudden changes in the current due to electronic commutation and thereby reduces the torque ripple.

\section{Filter Design}

The selection of LC component present in the filter plays a major role in the performance of the drive. The charging and discharging of the capacitor improves the quality of the voltage given to the motor. This filter possesses the advantages of both L-filter and C-filter. In addition, ripple factor in L-C filter has lower value than obtained by either $\mathrm{L}$-filter or $\mathrm{C}$-filter for the same values of $\mathrm{L}$ and $\mathrm{C}$.

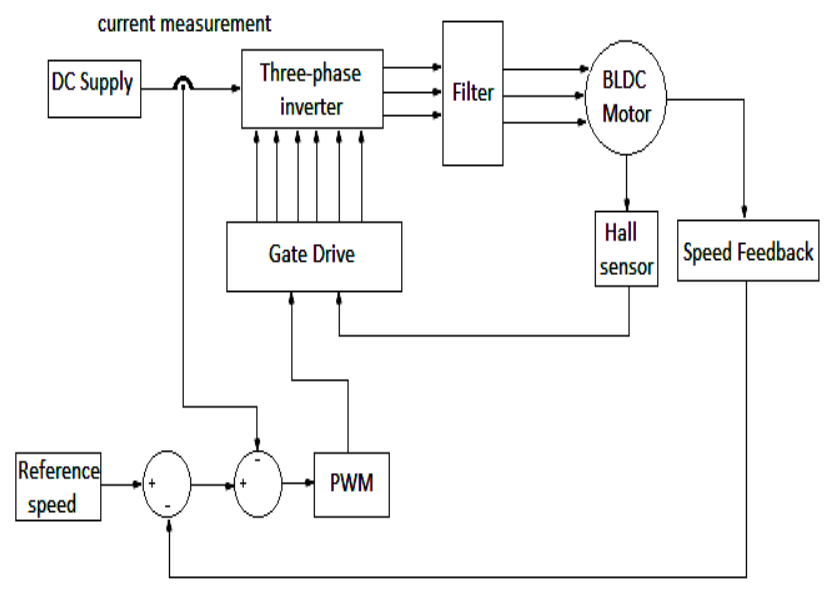

Figure 3. Block diagram of a voltage controller

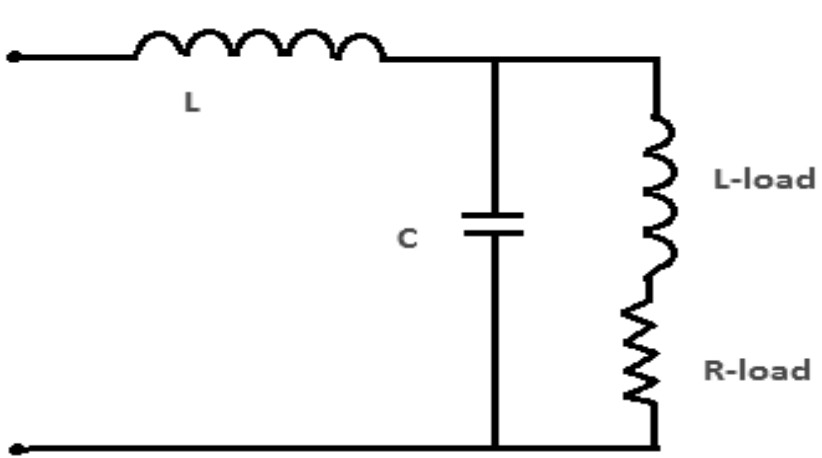

Figure 4. Equivalent LC filter for one phase

Fig.4 shows the equivalent circuit of L-C filter for reducing the ripple from the output voltage. The inductor current rating should be equal to the current ratings of the motor. The value of filter capacitor $\mathrm{C}$ can be calculated by

$$
\mathrm{C}=\frac{10}{2 \omega \sqrt{R^{2}+\left(2 \omega L_{L}\right)^{2}}}
$$

$\mathrm{R}$ is the load resistance and $\mathrm{L}_{\mathrm{L}}$ is the load inductance. The value of inductor $\mathrm{L}$ obtained by

$\mathrm{R}$ is the load resistance and $\mathrm{L}_{\mathrm{L}}$ is the load inductance. The value of inductor $\mathrm{L}$ obtained by

$$
\mathrm{VRF}=\frac{\sqrt{2}}{3}\left[\frac{1}{(2 \omega)^{2} L C-1}\right]
$$

VRF is voltage ripple factor. According to IEEE standard maximum allowable range to ripples is up to $10 \%$.So we are taking VRF as 0.01 and $\mathrm{L}$ value is calculated using known value of $\mathrm{C}$.

\section{Simulation Results}

Fig.5.(a) shows the three phase armature current waveform of BLDC motor with current control mode. Fig.5.(b) shows the armature current waveform of BLDC motor with voltage control mode. 
The current waveform in current control method is well settled and linear compared to voltage control waveform. Fig.6 shows the speed waveforms with voltage controller and the current controller with two level and multilevel inverter.

The Fig. 7 shows the torque waveform of BLDC motor in current control mode with two level and multilevel inverter and voltage control mode with two level inverter.

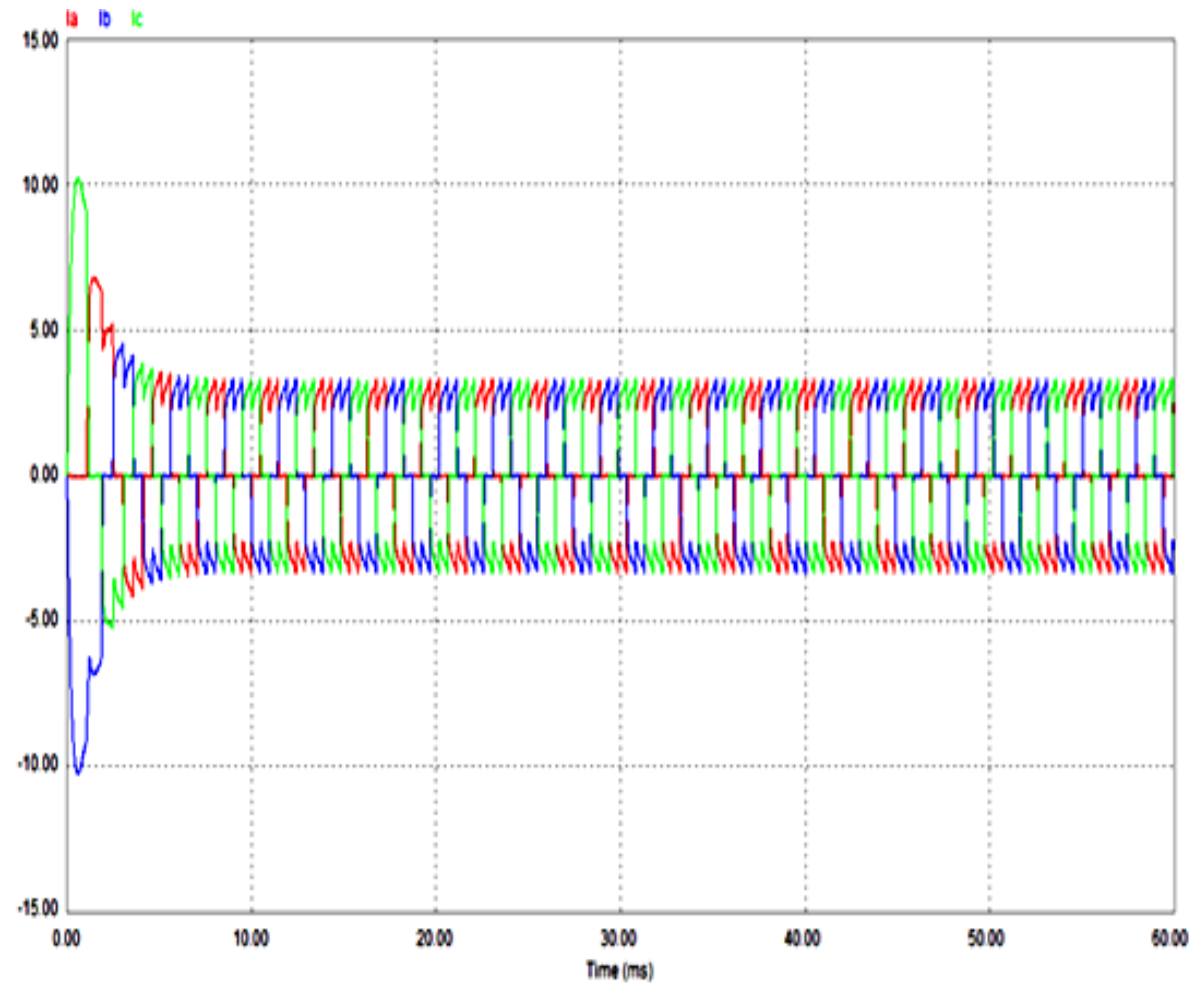

Figure 5(a). Three phase current waveform in current control method

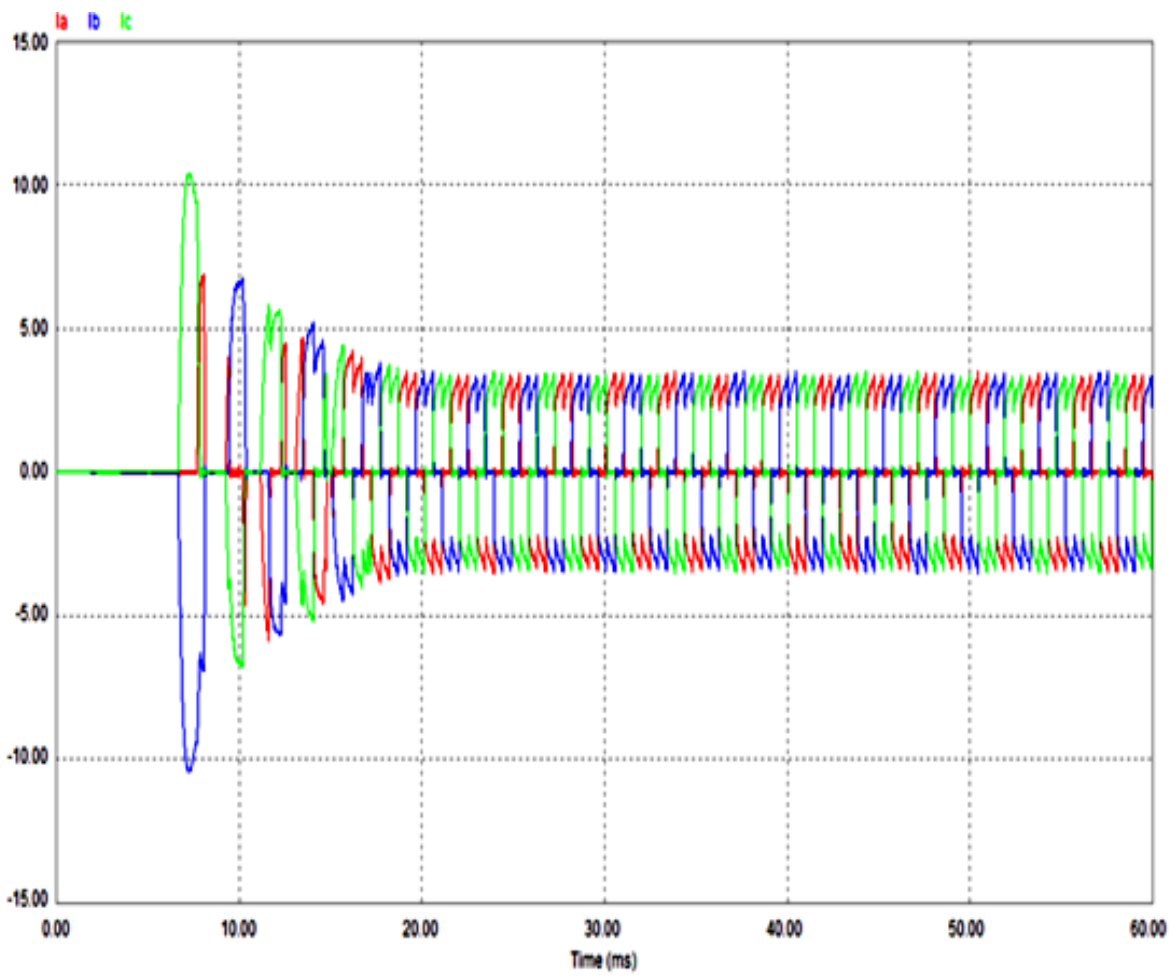

Figure 5(b). Three phase current waveform in voltage control method 


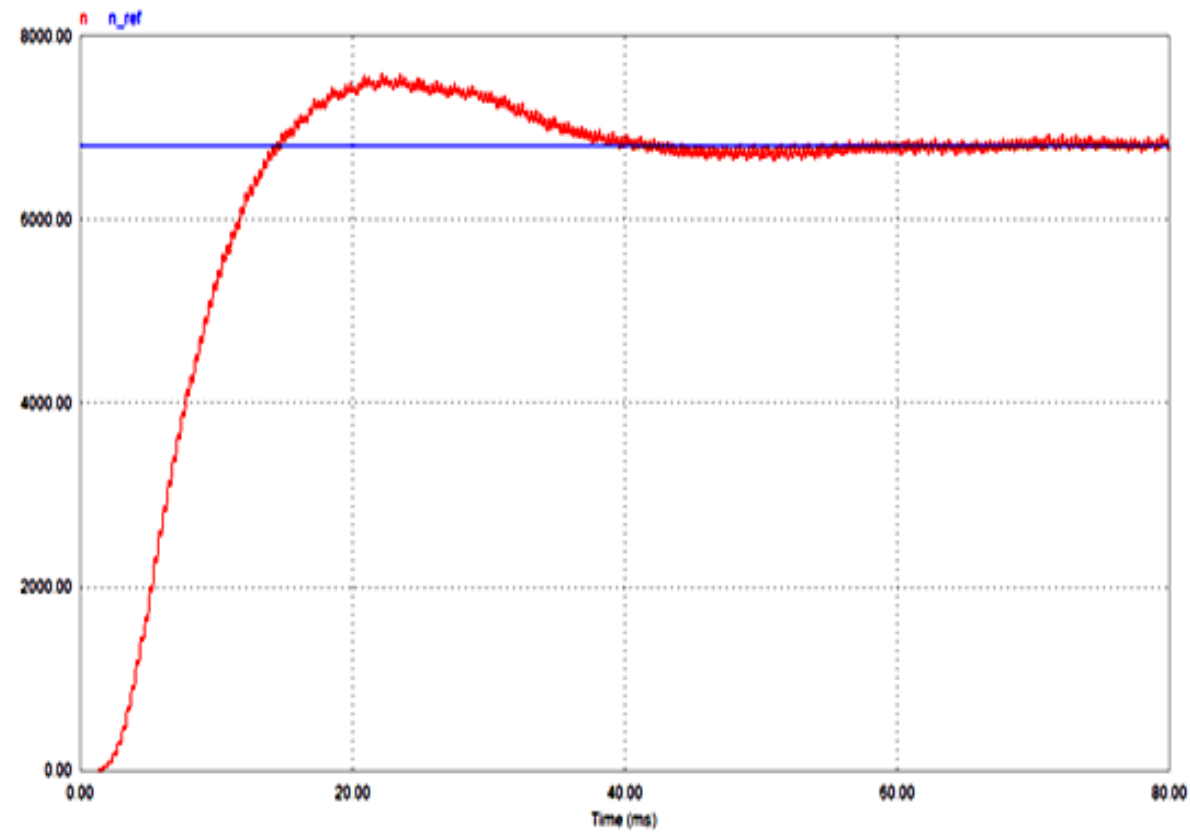

Figure 6(a). Speed response with voltage controller

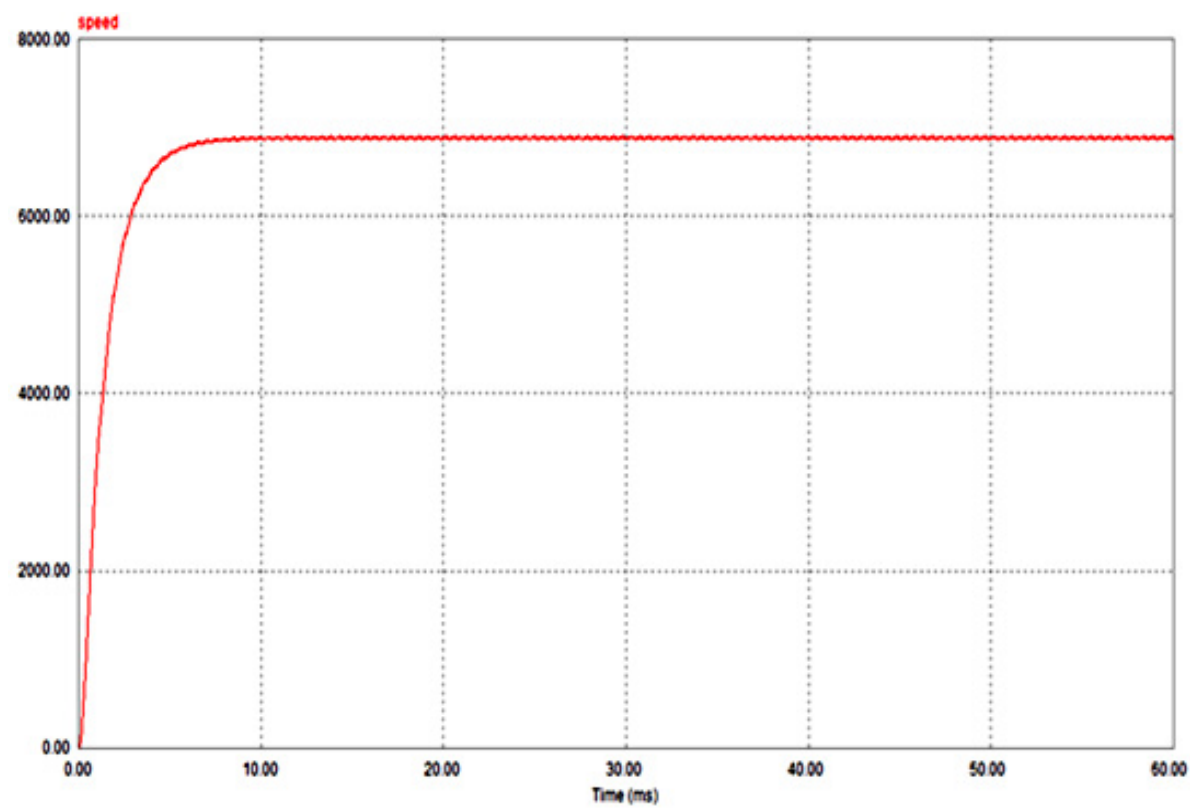

Figure 6(b). Speed response in current control method with two level inverter 


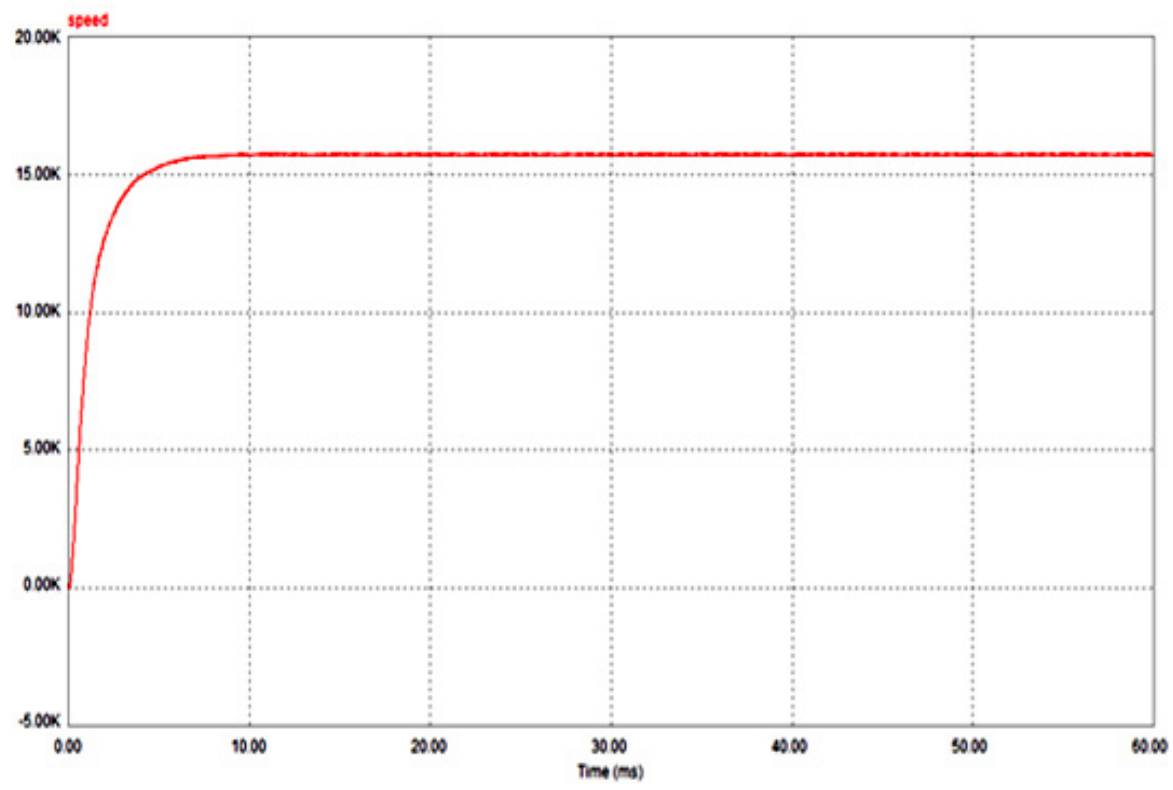

Figure 6(c). Speed response in current control method with multi-level inverter

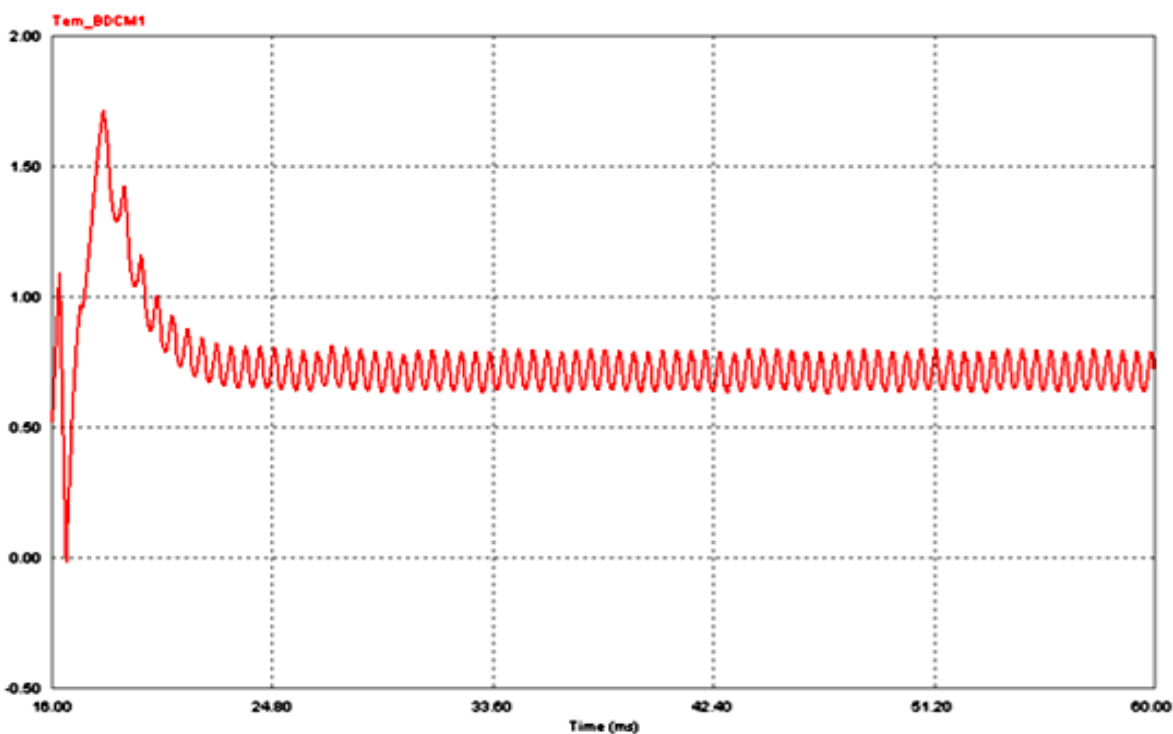

Figure 7(a). Torque waveform of BLDC motor with voltage controller 


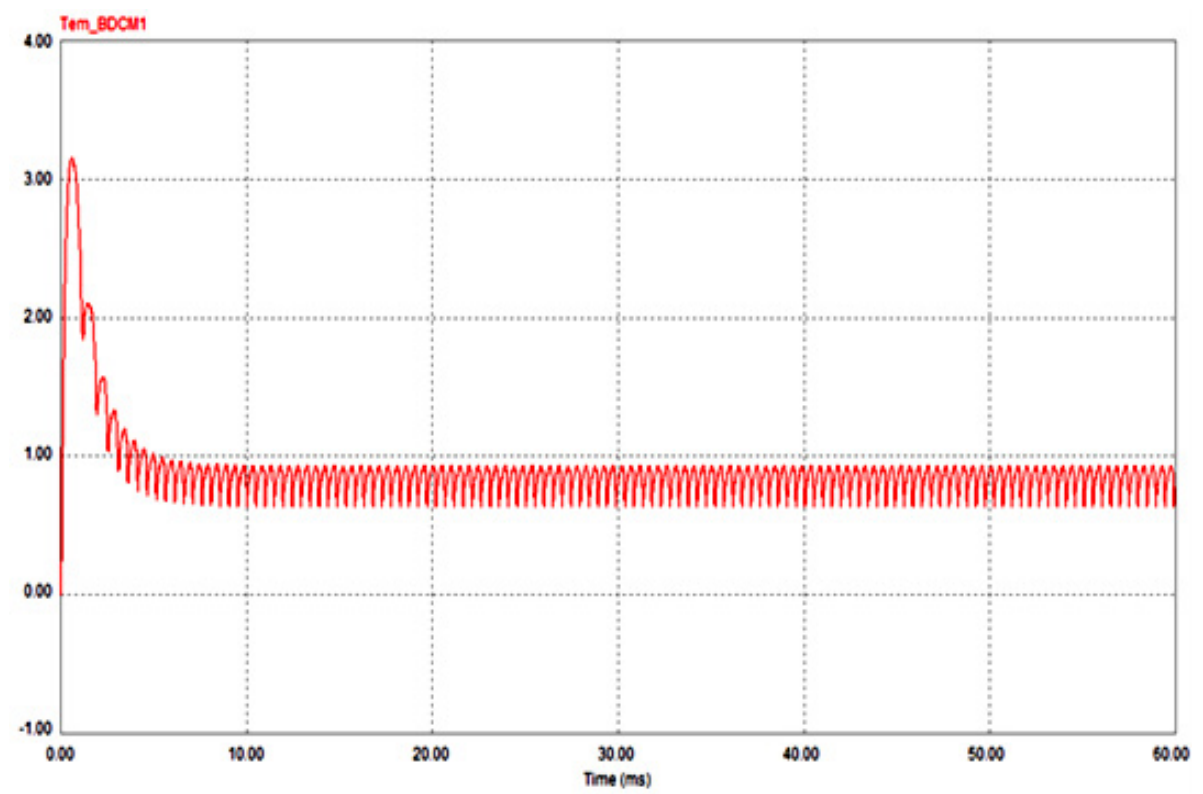

Figure 7(b). Torque waveform in current control method with two level inverter

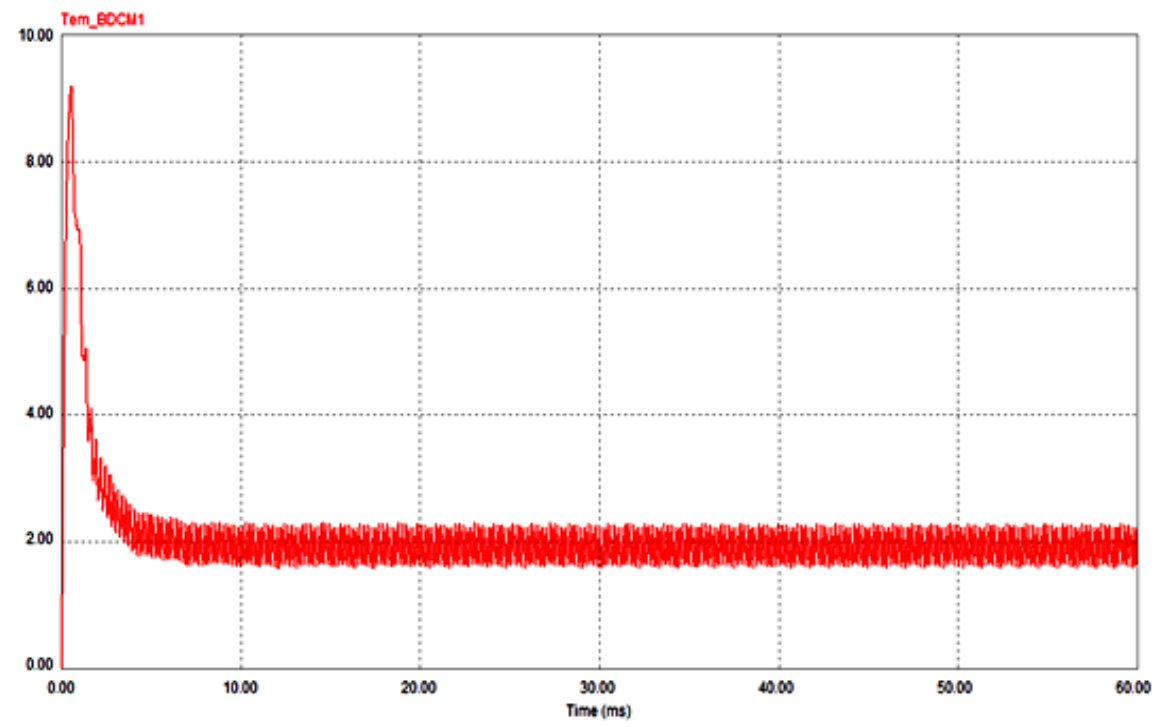

Figure 7(c). Torque waveform in current control method with multilevel inverter

\section{Torque Ripple and FFT Analysis}

Torque ripple is defined as periodic increase and decrease in output torque. .The formula for finding the torque ripple the percentage of the difference between the maximum torque and the minimum torque compared to the average torque. It is calculated by the following formula.

$$
\text { Amount of Torque ripple }=\frac{\text { Tmax }- \text { Tmin }}{\text { Tavg }} * 100
$$

Fig.8 shows the FFT analysis of phase currents with voltage and current controller. The order of the harmonics is very much reduced in current control mode compared to voltage control mode.

The following table. 1 shows the amount of Torque ripple with different type of controllers.

Table 1. Amount of torque ripples with different controller.

\begin{tabular}{|c|c|}
\hline Type of controller & Amount of Torque ripple in \% \\
\hline Voltage controller with Filters & $41.5 \%$ \\
\hline $\begin{array}{c}\text { Current controller with two level } \\
\text { inverter }\end{array}$ & $33.11 \%$ \\
\hline $\begin{array}{c}\text { Current controller with multilevel } \\
\text { inverter }\end{array}$ & $18.6 \%$ \\
\hline
\end{tabular}




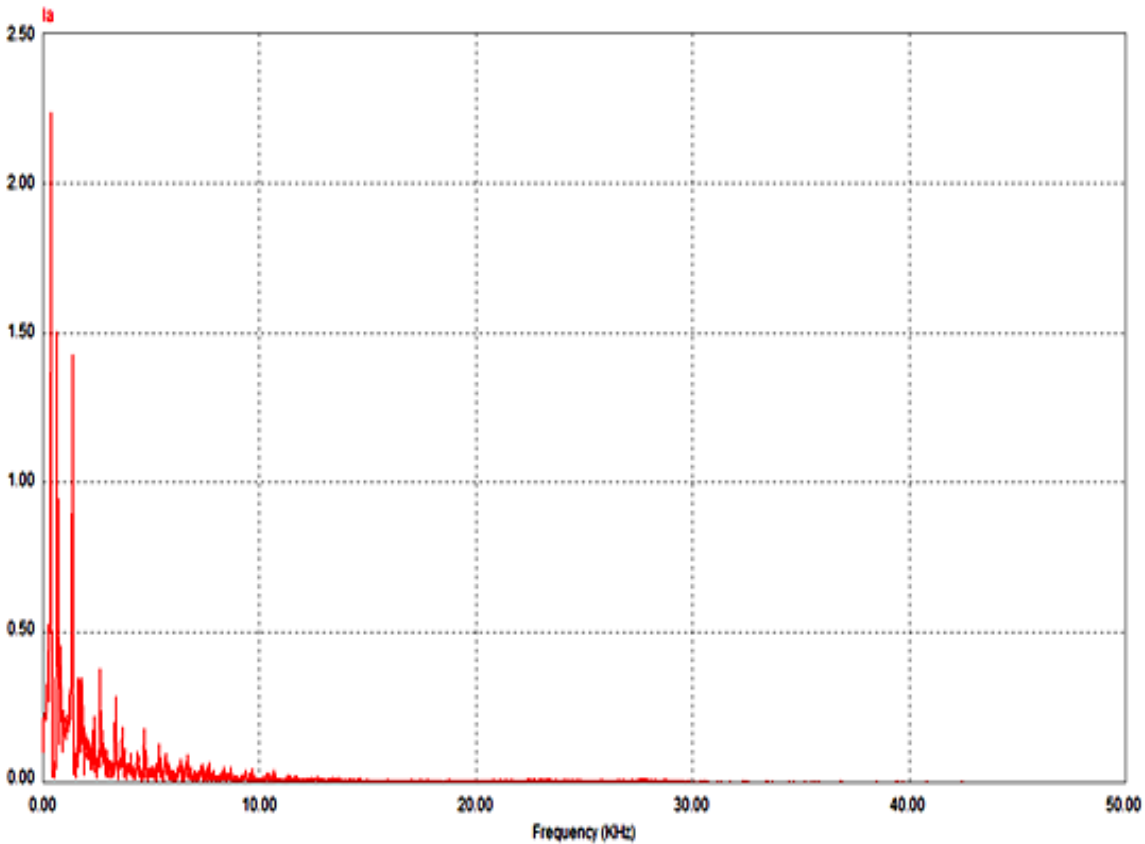

Figure 8(a). FFT analysis of phase current in voltage controller mode

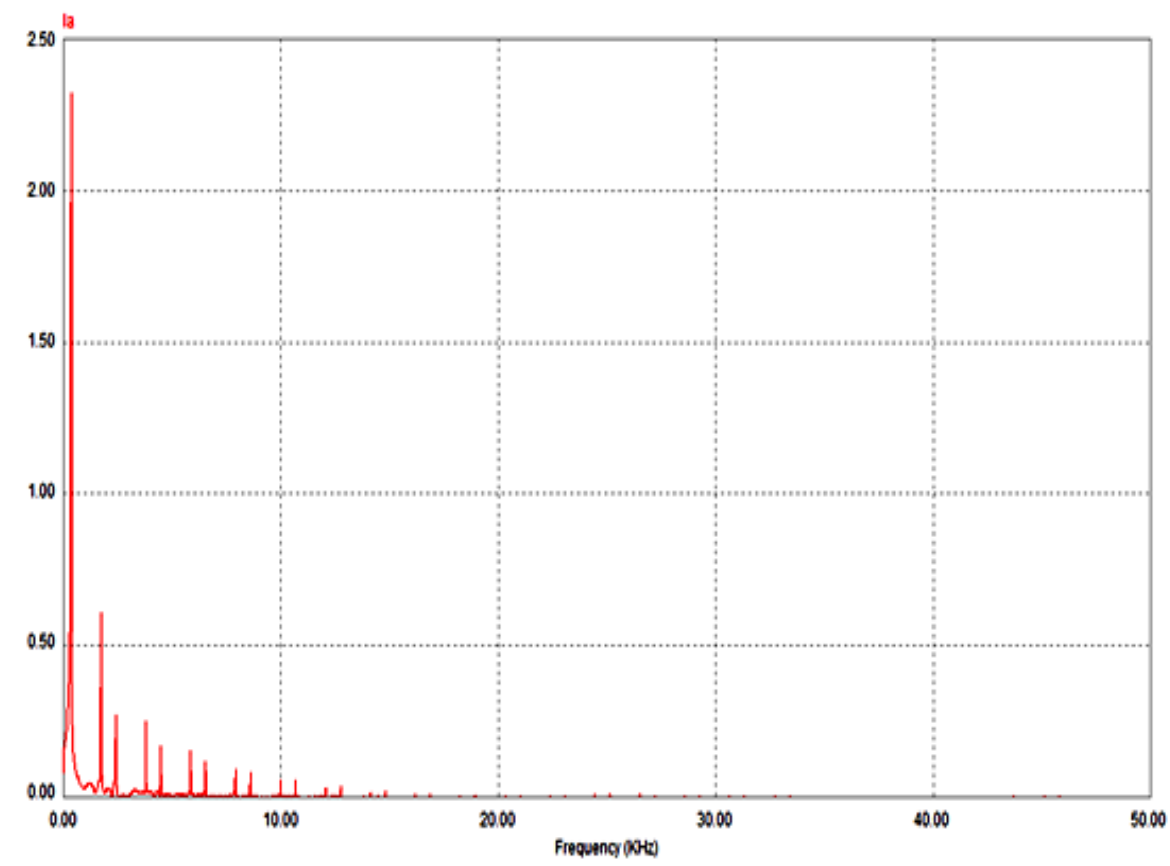

Figure 8(b). FFT analysis of phase current in current controller mode with two level inverter 


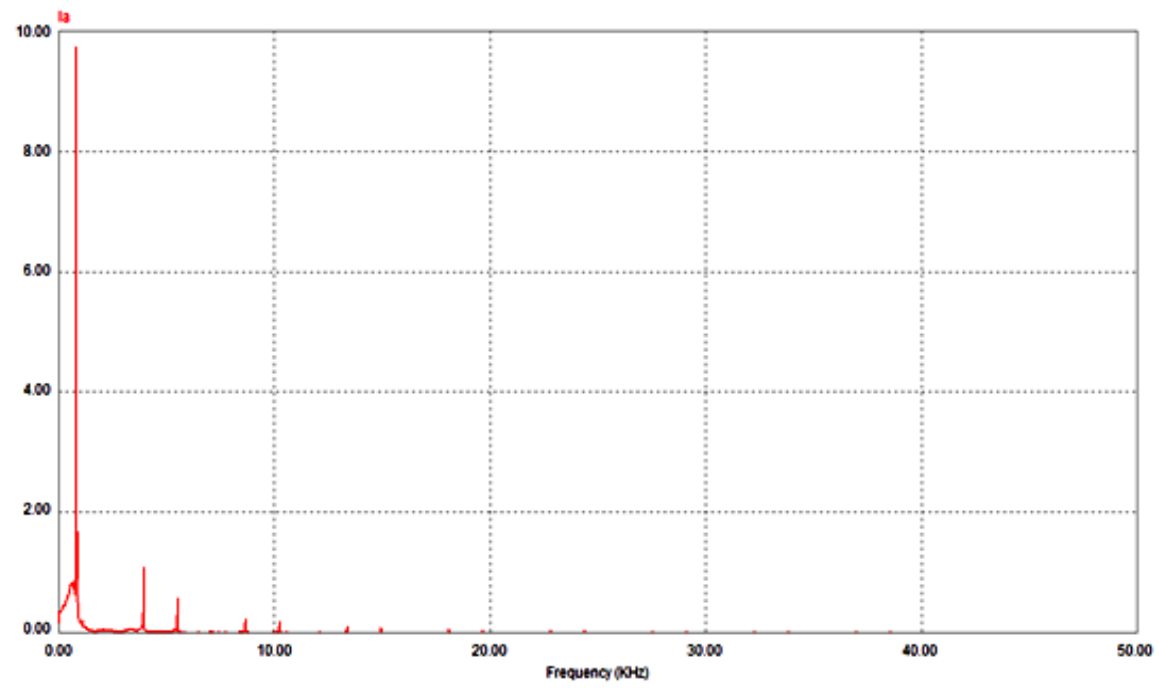

Figure 8(c). FFT analysis of phase current in current controller mode with multilevel inverter.

\section{Conclusion}

In this paper the different control strategy for minimizing the torque ripple of brushless dc motor is proposed. The amount of torque ripple in Brushless DC Motor with voltage and current controller is calculated. The phase current waveform and speed waveform are discussed. Hence the suitable controller to minimize torque ripple is current control method. As the torque ripple reduces, it is also understood that when torque ripple reduces the harmonics also reduces dependently and there by performance enhancement of the machine is improved.

\section{REFERENCES}

[1] Jiancheng Fang, Haitao Li, and Bangcheng Han. "Torque Ripple Reduction in BLDC Torque Motor With Nonideal Back EMF ". IEEE TRANSACTIONS ON POWER ELECTRONICS, VOL. 27, NO. 11, NOVEMBER 2011.

[2] Ki-Yong Nam, Woo-Taik Lee, Choon-Man Lee, and Jung-Pyo Hong. "Reducing Torque Ripple of Brushless DC Motor by Varying Input Voltage". IEEE TRANSACTIONS ON MAGNETICS, VOL. 42, NO. 4, APRIL 2006.

[3] S. Ziaeinejad, Y. Sangsefidi, and A. Shoulaie. "Analysis of Commutation Torque Ripple of BLDC Motors and a Simple Method for Its Reduction”. 2011 International Conference on Electrical Engineering and Informatics 17-19 July 2011, Bandung, Indonesia.

[4] Kwang-Woon Lee, Dae-Kyong Kim, Tae-Duck Kim, and Jae-Young Choi. "Commutation Torque Ripple Reduction in a Position Sensorless Brushless DC Motor Drive". 2004.35rh Annul IEEE Power Electronics Specialists Conference.

[5] Wael A. Salah,Dahaman Ishak and Khaleel J. Hammadi "PWM SWITCHING STRATEGY FOR TORQUE RIPPLE MINIMIZATION IN BLDC MOTOR" Journal of ELECTRICAL ENGINEERING, VOL. 62, NO. 3, 2011, $141-146$.

[6] Vanisri A and Devarajan N "Torque Ripple Minimization in Indirect Position Detection of Permanent Magnet Brushless DC Motor" European Journal of Scientific Research ISSN 1450-216X Vol.65 No.4 (2011), pp. 481-489

[7] A. Albert Rajan, Dr. S. Vasantharathna."Harmonics and Torque Ripple Minimization using L-C Filter for Brushless DC Motors". International Journal of Recent Trends in Engineering, Vol 2, No. 5, November 2009.

[8] Lee and Jong-Bae Y. "a Low cost speed control system of Brushless de motor using Fuzzy logic",Information, Decision and control,page 433-437,1999.

[9] Varatharaju VM,Mathur B L and Udhayakumar.K"A comparative Study with modeling and Simulation of Torque Ripple Reduction Techniques in BLDC Motor" European Journal of Scientific Research ISSN 1450-216X, pp.295-305,vol.52 No.3 (2011).

[10] R.Goutham Govind Raju, S.John Powl, A.Sathishkumar and P.Sivaprakasam "Mitigation of Torque for Brushless DC Motor: Modeling and Control" International Journal of Scientific \& Engineering Research Volume 3, Issue 5, May2012.

[11] B.Nogarede and M.Lajoie-Mazenc,"Torque ripple minimization methods in sinusoidal fed synchronous permanent magnet machines",in Proc IEEE Conf.Elec.Machines \& Drives, Sept.1991,pp-41-45. 